\title{
PROPOSTA DE PLANEJAMENTO PARA A ORGANIZAÇÃO DO FLUXO DE MOLDES NO PROCESSO DE SET-UP: UM ESTUDO COM FOCO NO DESENVOLVIMENTO ORGANIZACIONAL
}

\author{
Talita Aparecida de Araújo Alves ${ }^{1}$ \\ Jusirmar Alves da $\mathrm{Cruz}^{2}$ \\ Rosilda do Rocio do Vale ${ }^{3}$ \\ Dariane Cristina Catapan ${ }^{4}$
}

\section{RESUMO}

O objetivo do estudo foi implantar instruções de trabalho para organizar o fluxo dos moldes no setor produtivo da empresa Freso, visando à redução da oscilação no tempo de set-up na máquina SHUTTLE DC 3.50. O estudo teve início com a verificação e localização atual dos moldes, e para seu desenvolvimento foram utilizados como metodologia técnicas e métodos para a coleta; a análise dos dados e implantação, a pesquisa de campo e, consequentemente, a coleta de dados foram realizadas por meio de entrevista informal e brainstorming com os colaboradores bem como com o gestor de produção. A pesquisa bibliográfica utilizada foi baseada em assuntos relacionados à "Gestão da Produção, com foco no tempo de set-up e instrução de trabalho". Após escolhido o modelo ideal de instrução de trabalho, foi realizado o treinamento para os colaboradores. A oscilação no tempo de set-up é um fator encontrado na empresa Freso, o qual impactou na produção.

Palavras-chave: Gestão da Produção. Instrução de trabalho. Oscilação. Tempo de set-up.

\begin{abstract}
The objective was to implement work instructions to organize the flow of the molds in the productive sector of Freso company in order to reduce the oscillation in the set-up time at SHUTTLE DC 3.50 machine. The study began with checking and current location of the molds, and the development of it was used as methodology techniques and methods for collection; data analysis and deployment, field research and therefore the data collection was carried out through informal interview and brainstorming with employees as well as the production manager. The literature used was based on issues related to the "Management of Production, focusing on setup time and work instruction". After choosing the ideal model of work instruction was held training for employees. The oscillation in the set-up time is a factor found in Freso company, which impacted on production.
\end{abstract}

Key-words: Production Management. Work instruction. Oscillation; Set-up time.

\footnotetext{
${ }^{1}$ Faculdade da Indústria (IEL). Graduada em Administração pela Faculdade da Indústria (IEL). Av. Rui Barbosa, 5881, Afonso Pena, São José dos Pinhais, PR, CEP: 83040-550. E-mail: talita.alves@ielpr.org.br

${ }^{2}$ Faculdade da Indústria (IEL). Professor da Faculdade da Indústria (IEL). Formação técnica em Eletrotécnica (Instituto Politécnico Estadual do Paraná), bacharelado em Administração com Habilitação em Gestão da Qualidade (FAMEC), pós-graduação Lato Sensu em Gestão de Manufatura (UTFPR) e mestrado em Administração (Universidade Positivo). Av. Rui Barbosa, 5881, Afonso Pena, São José dos Pinhais, PR, CEP: 83040-550. E-mail: jusirmar.cruz@ielpr.org.br

${ }^{3}$ Faculdade da Indústria (IEL). Professora da Faculdade da Indústria (IEL). Mestre em Administração pela Pontifícia Universidade Católica do Paraná (PUCPR) ( 2014). Graduada em Administração de Empresas pela Fundação de Estudos Sociais do Paraná (FESP) (2004); pós-graduada em Finanças Corporativa pela FESP (2006); MBA em Gestão Empresarial pela Faculdade Spei (2007); Tecnóloga em Gestão Pública pela Escola Técnica UFPR (2009). Av. Rui Barbosa, 5881, Afonso Pena, São José dos Pinhais, PR, CEP: 83040-550. E-mail: rosilda.vale@ielpr.org.br

${ }^{4}$ Faculdade da Indústria (IEL). Professora da Faculdade da Indústria (IEL). Formada em Medicina Veterinária, pós-graduada em Gestão Ambiental e Desenvolvimento Sustentável e mestre em Ciência Animal. Av. Rui Barbosa, 5881, Afonso Pena, São José dos Pinhais, PR, CEP: 83040-550. E-mail: darianecatapan@yahoo.com.br
} 


\section{Introdução}

Para que as empresas se desenvolvam e cresçam, reunindo mais pessoas e recursos, e para que seus objetivos de competitividade sejam alcançados, elas precisam buscar estratégias de melhorias em seus processos e produtos. Assim, torna-se necessário criar uma estrutura empresarial que regule as relações entre os elementos da empresa e sustente as suas atividades, possibilitando manter-se competitiva no mercado. Nas empresas existem atividades que, se realizadas de forma indevida, agregam custos aos produtos e nenhum benefício ao cliente. Essas atividades se transformaram em motivo de preocupação para as empresas, e, quando minimizadas, reduzem custos e aumentam a produtividade, tornando a mais competitiva no mercado (TEODORO et al., 2002).

Conforme Martins e Laugeni (2010, p. 88), “o tempo de set-up é o tempo gasto na nova preparação do equipamento até o instante em que a produção é liberada". Enquanto Corrêa e Corrêa (2009) destacam a necessidade de redução desse tempo de set-up, pois dentro de um sistema produtivo existem vários fatores que podem comprometer o desempenho da produção, entre eles os tempos de preparação das máquinas (set-up). Martins e Laugeni (2010, p. 84) abordam a respeito da eficiência e que os tempos-padrões de produção são influenciados pelo tipo do fluxo de material dentro da empresa, processo escolhido, tecnologia utilizada e características do trabalho que está sendo analisado.

Diante do exposto, a pesquisa buscou analisar como reduzir a oscilação no tempo de set-up na máquina SHUTTLE DC 3.50 na empresa Freso - Brinquedos e Playgrounds e, consequentemente, implantar instrução de trabalho para organizar o fluxo dos moldes visando à redução da oscilação no tempo de set-up da máquina citada.

\section{Metodologia}

A pesquisa é um estudo de caso qualitativo e descritivo. De acordo com Collis e Hussey (2005, p. 178), "uma pesquisa de dados qualitativos nada mais é do que uma opinião clara a respeito da observação de fatos, entrevistas, fotos, acontecimentos e conhecimento empírico sobre determinado assunto". 
A realização da pesquisa de campo ocorreu por meio de observações, entrevista informal e brainstorming. Para apresentação e análise dos dados foram utilizados gráficos.

\section{Fundamentação teórica}

O embasamento teórico do estudo apresenta temas relacionados ao setor de produção.

\subsection{Gestão de processos}

De acordo com Paim (2009, p. 24), "gestão de processo pode ser estudada e entendida como uma forma de reduzir o tempo entre a identificação de um problema de desempenho em algum processo e a implementação de algumas soluções necessárias". Portanto, para que esses resultados sejam alcançados, as ações e as análises dos processos devem ser muito bem estruturadas, permitindo que os processos sejam diagnosticados com rapidez e identificando soluções no menor intervalo de tempo e custos possíveis.

A melhoria de processos pode ser uma ação básica para as organizações responderem às mudanças que podem acontecer em seu ambiente de atuação e para manter o sistema produtivo competitivo. Essa capacidade tem sido vista atualmente como uma forma eficaz de promover integração, dinâmica, flexibilidade e inovação nas organizações. Os resultados e benefícios que podem ser alcançados: melhoria do fluxo de informações; padronização dos processos em função de definição de um referencial de conformidade; redução de tempo e custos dos processos; aumento da satisfação dos clientes; aumento da produtividade dos trabalhadores e redução de defeitos (PAIM, 2009).

\subsection{Processos produtivos}

Na concepção de Martins e Laugeni (2010, p. 96), processo em uma empresa industrial "é o percurso realizado por um material desde que entra na empresa até que dela saia, com um grau determinado de transformação".

Processos "são o arranjo de recursos que produzem alguma mistura de produtos e serviços". Já os processos produtivos são caracterizados "com o mesmo conceito, porém com particularidades como: volume de output, variedade de output, variação da 
demanda do output e o grau de visibilidade que os consumidores possuem da produção do output" (SLACK, 2009, p. 13 e 16).

De acordo com Tubino (2009, p. 113), para que ocorra um processo produtivo adequado, é feito um programa de produção que diz respeito aos dados dos funcionários. Deve haver exatidão nas informações para compor os planos produtivos da empresa: os de engenharia, marketing, tempos-padrões de operações, níveis de estoques e lead times. O próprio autor conceitua lead time como "uma medida do tempo gasto pelo sistema produtivo para transformar matérias-primas em produtos acabados".

\subsection{Set-up}

Alves (2006, p. 9) comenta que atualmente a obrigação de baixos tempos de setups é maior do que antigamente, pela necessidade das empresas em introduzir a produção enxuta, uma vez que o baixo set-up é um dos pilares desse sistema produtivo. A diminuição do tempo de set-up para resolver problemas de capacidade tem um ganho facilmente calculado, que geralmente é a não necessidade de se comprar uma nova máquina. Os benefícios na redução do set-up, segundo Mcintosh (1996 apud Alves, 2006), são: reduzir recursos (ex.: menos necessidade de mão de obra, menos necessidade da habilidade da mão de obra); aumentar a flexibilidade; aumentar o controle do processo (ex.: aumentar a qualidade do produto, aumentar a confiabilidade do processo); reduzir o tempo de parada de equipamentos; e reduzir inventário.

Set-up, ou preparação, seria o trabalho feito para colocar o equipamento em condições de produzir uma nova peça com qualidade em produção normal. O tempo de set-up constitui o tempo gasto na nova preparação do equipamento até o instante em que a produção é liberada (MARTINS; LAUGENI, 2010, p. 88). Ainda no entender de Martins e Laugeni (2010, p. 88), o set-up costuma ser visto como uma atividade acíclica (que não tem ciclo) dentro do processo de produção, porque ocorre cada vez que é produzido um lote de peças e não somente uma peça.

\subsection{Treinamento}

Spector (2006, p. 172) destaca que o treinamento "é uma das principais atividades das organizações, sendo necessário tanto para novos funcionários como para os experientes". É no treinamento que os novos funcionários devem aprender como a 
empresa funciona e como executar seu trabalho. Os funcionários experientes devem aprender a se manter atualizados com as mudanças que ocorrem.

Para Milkovich e Boudreu (2010, p. 338) "treinamento é um processo que promove a aquisição de habilidades conceitos ou atitudes, melhorando a adequação das características do funcionário às exigências do seu cargo". Lacombe (2011, p. 381) aborda que "as empresas que não treinam e desenvolvem seus funcionários, podem enfrentar dificuldades competitivas por falta de gente preparada para seus cargos".

\subsubsection{Folha de processo}

Para que as empresas adquiram maior participação no mercado e garantia dos ganhos que possibilitarão novos investimentos, elas utilizam uma ferramenta na questão de tempos e movimentos na manufatura. Essa ferramenta contribui para diminuir a variabilidade nos processos, além de aumentar o desempenho dos trabalhadores. Essa técnica volta-se para a redução dos desperdícios dos movimentos e otimização dos recursos e do tempo de trabalho, consequentemente, a organização ganha poder competitivo (ALMEIDA, 2009, p. 46).

De acordo com Junior et al. (2006), após ter-se encontrado o melhor modo de execução da tarefa, é essencial que se faça um registro permanente, em que esse documento possa ser usado como folha de instrução para operador ou como auxiliar ao instrutor durante o treinamento do trabalhador. "A Folha de Processo ou de instrução pode ser considerada uma ferramenta de auxílio na busca pela padronização das atividades na manufatura" (ALMEIDA, 2009, p. 13).

Almeida (2009, p. 46) ainda comenta que "a elaboração da Folha de Processo tem por objetivo procurar promover o cumprimento das metas de produção da organização, melhorar os processos de fabricação e a eficiência humana".

Os registros ou folhas de instrução são normalmente preparados pela pessoa que executa o estudo de tempos e movimentos ou então pela pessoa que supervisiona a investigação. Eles contêm detalhes completos da operação, os elementos que compõem o trabalho, as ferramentas e os dispositivos utilizados, entre outras informações. Uma vez que o método tenha sido padronizado e colocado em execução, torna-se necessária a vigilância constante por parte da administração a fim de que o padrão seja mantido (JÚNIOR et al, 2006, p. 112). 
Essa folha de processos conforme Almeida (2009, p. 48) tem como objetivo padronizar os processos fabris da empresa, auxiliar os supervisores no controle da produção e no treinamento de seus operários. Ela visa registrar as sequências de operações, indicando o material utilizado, a sequência correta de cada fase, o lugar de trabalho de cada funcionário, o equipamento apropriado, as ferramentas que devem ser usadas e o tempo-padrão de todo o processo.

\subsection{Fluxo de materiais}

O fluxo de materiais tem por finalidade assegurar o contínuo abastecimento dos itens que entram na fabricação dos produtos (MESSIAS, 1997, p. 23). Enquanto para Moura (2005) o fluxo de materiais pode ser definido como o caminho que o recurso a ser transformado percorre durante todo o processo produtivo, representando um fator de influência direta no tempo de produção. Na visão de Teodoro et al. (2002, p. 7), “o fluxo de material eficiente é aquele que resulta no percurso mais curto dos funcionários e dos equipamentos de movimentação".

Para obter uma visão mais ampla do fluxo de materiais, uma técnica de uso universal é o fluxograma, que, por meio de símbolos convencionais, representa a sequência de atividades. De acordo com Oliveira (2002, p. 248), "fluxograma é a representação gráfica que apresenta a sequência de um trabalho de forma analítica, caracterizando operações, os responsáveis e/ou unidades organizacionais envolvidas no processo".

\subsection{Organização do fluxo de moldes no processo de set-up}

Por meio de estudos de métodos de trabalho, fluxo de materiais e informações coletadas na empresa, chegou-se à melhor proposta para implantar a instrução de trabalho para a máquina SHUTTLE DC 3.50. Como a empresa em estudo possui três turnos, A, B e C, o fluxo dos moldes durante o set-up poderá ser organizado conforme o Quadro 1.

Quadro 1 - Fluxo dos moldes durante o set-up

\begin{tabular}{|c|c|l|}
\hline Turno & Período & \multicolumn{1}{c|}{ Atividades a serem executadas } \\
\hline A & Manhã e tarde & Realizará o set-up e irá somente trocar os moldes sem precisar buscá-los. \\
\hline B & Tarde & $\begin{array}{l}\text { Apanhará os moldes que foram trocados pelo turno A e os guardará de } \\
\text { forma organizada no estoque de moldes. }\end{array}$ \\
\hline
\end{tabular}




\begin{tabular}{|c|l|l|}
\hline C & Noite & $\begin{array}{l}\text { Expediente irá identificar, separar os moldes para a produção do dia } \\
\text { seguinte e deixará os moldes do lado da máquina SHUTTLE DC 3.50. }\end{array}$ \\
\hline
\end{tabular}

Fonte: elaborado pelos autores (2015).

E assim torna-se um ciclo no qual todos os turnos devem cooperar, conforme Figura 1.

Figura 1 - fluxo do processo dos moldes para o set-up

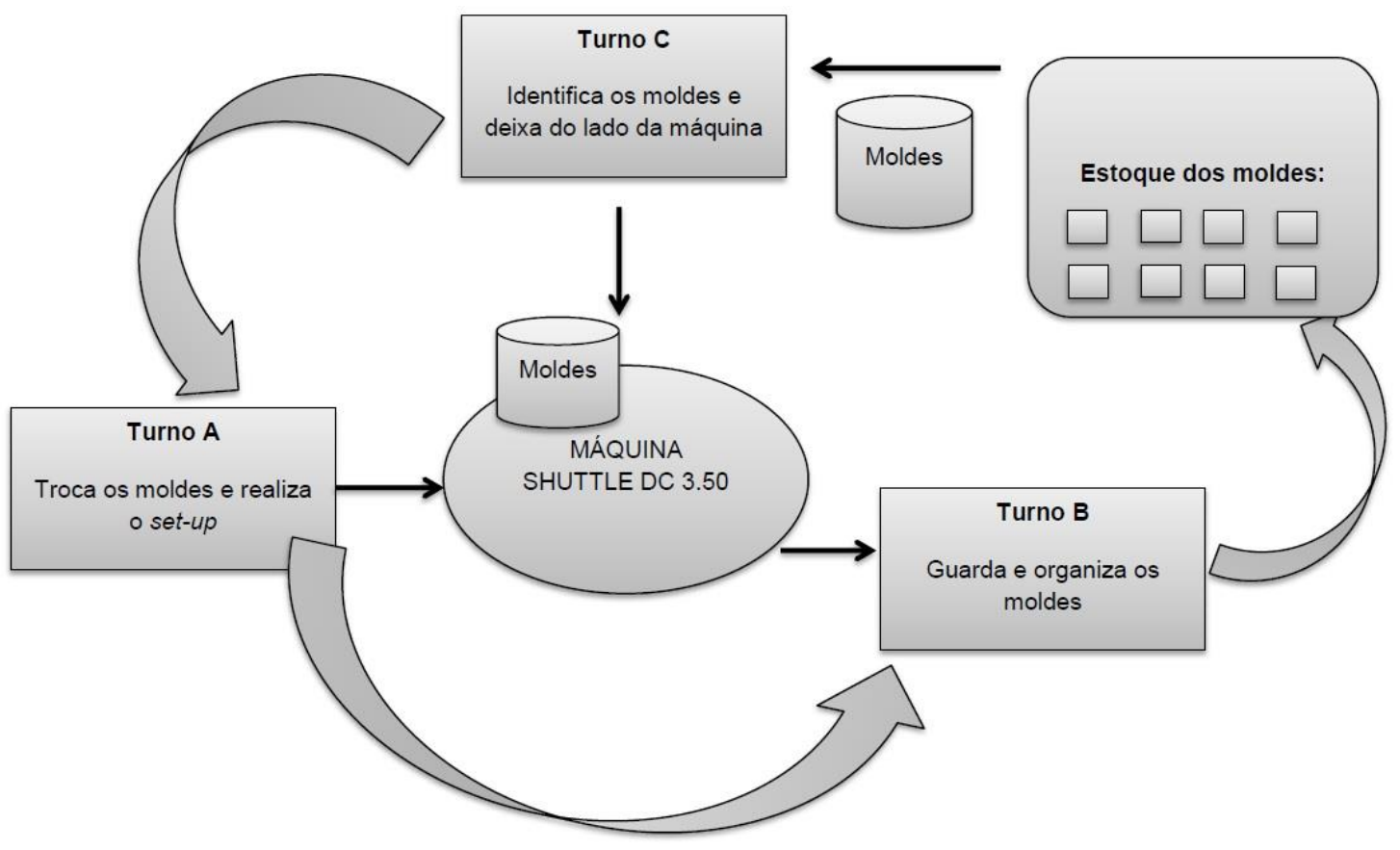

Fonte: elaborada pelos autores (2015).

De acordo com o gestor da produção, todos os dias às 16 horas aproximadamente o setor de vendas entrega ao setor de produção a OP (Ordem de Produção) do dia seguinte. A partir daí, o turno C fica responsável pela identificação dos moldes e pela movimentação até a máquina, e deverá identificar quais moldes estarão disponíveis para o dia seguinte e que atividade poderá ser realizada no final do expediente. O turno $\mathrm{C}$ deve verificar a localização dos moldes, para saber se estão de acordo com a demanda de produção atual, ou seja, se os moldes mais utilizados estão com livre acesso à produção, isso será definido conforme a demanda, ou seja, será estipulado quais moldes serão mais utilizados e quais serão menos utilizados, para colocá-los de forma organizada em seu estoque ou devido lugar.

A partir da situação analisada na empresa e com base na teoria já abordada, procurou-se elaborar uma folha de instrução de trabalho para que operadores e gestores, bem como os demais envolvidos, possam verificar como o processo será realizado e documentado na área de produção, conforme Quadro 2. 
Quadro 2 - Folha de instrução de trabalho para à freso

\begin{tabular}{|c|c|c|c|c|c|}
\hline \multicolumn{5}{|c|}{$\begin{array}{l}\text { INSTRUÇÕES DE TRABALHOPARA A ORGANIZAÇÃO DO } \\
\text { FLUXO DOS MOLDES }\end{array}$} & \\
\hline \multicolumn{5}{|c|}{ Processo: Set-up } & \multirow{2}{*}{$\begin{array}{l}\text { Equipamento: Máquina SHUTTLE DC } \\
3.50 \\
\text { Material: Moldes }\end{array}$} \\
\hline \multicolumn{5}{|c|}{$\begin{array}{l}\text { Executor: Operadores da máquina SHUTTLE DC } 3.50 \text { de todos os } \\
\text { turnos }\end{array}$} & \\
\hline \multicolumn{6}{|c|}{$\begin{array}{l}\text { Atividades a serem realizadas pelos operadores na máquina SHUTTLE DC } 3.50 \text { para a organização do fluxo dos } \\
\text { moldes visando à redução da oscilação no tempo de set-up. }\end{array}$} \\
\hline Passo & Turno & \multicolumn{4}{|c|}{ Descrição das atividades } \\
\hline 1 & $\mathrm{C}$ & \multicolumn{4}{|c|}{ Identificar os moldes da produção para o dia seguinte. } \\
\hline 2 & $\mathrm{C}$ & \multicolumn{4}{|c|}{ Levar os moldes identificados para o lado da máquina. } \\
\hline 3 & $\mathrm{~A}$ & \multicolumn{4}{|c|}{ Trocar os moldes e realizar o set-up. } \\
\hline 4 & A & \multicolumn{4}{|c|}{ Deixar os moldes que foram retirados da máquina durante o set-up do lado da máquina. } \\
\hline 5 & B & \multicolumn{4}{|c|}{ Pegar os moldes do lado da máquina e levá-los para o estoque. } \\
\hline 6 & B & \multicolumn{4}{|c|}{ Organizar os moldes a serem guardados. } \\
\hline \multicolumn{6}{|c|}{ Seguir o mesmo fluxo em todos os set-ups realizados. } \\
\hline \multicolumn{3}{|c|}{ Elaboração/Revisão: } & Data: & Revisão: 00 & Aprovação: \\
\hline
\end{tabular}

Fonte: elaborado pelos autores (2015).

Conforme o Quadro 2, a instrução de trabalho criada para os envolvidos no processo de set-up da empresa aborda vários campos para documentar e explicar como acontecerá o processo. O campo que diz respeito ao processo especifica qual é o processo que será trabalhado; o campo executor apresenta quem irá realizá-lo; o título identifica qual atividade será realizada; o campo equipamento representa em qual máquina será realizado e o campo material identifica o tipo de material que será utilizado para o andamento do processo. Então, existem dois campos que se referem à data e aprovação do que aconteceu e a utilização inicial da folha de instrução, relacionadas à aprovação do gestor responsável.

$\mathrm{Na}$ descrição das atividades se apresenta o que será realizado, ou seja, como acontecerá o processo, bem como é descrito ao lado qual o turno que irá realizá-lo.

Essa folha de instrução de trabalho foi apresentada aos envolvidos no processo de set-up para que pudessem conhecer a ferramenta e/ou documento que irão utilizar como um meio documentado.

\section{Treinamento com os envolvidos para a utilização da instrução de trabalho}

A partir da elaboração da folha de instrução de trabalho realizou-se o treinamento para os envolvidos no processo de set-up, o qual ocorreu no dia 8 de setembro de 2014. O horário e a quantidade de operadores por turno foram estipulados 
pelo gestor da área, sendo que no total participaram 18 colaboradores e cada treinamento teve duração média de 40 minutos. Foram abordados temas como: a importância para os operadores em reduzir a oscilação do set-up, a perda que o tempo de set-up representa na produção para a empresa. Para melhor entendimento dos colaboradores, foram utilizados dois gráficos os quais foram elaborados a partir de informações coletadas durante os 13 set-ups, acompanhados no primeiro semestre de 2014. Apresentando como foco principal do treinamento a implantação da folha de instrução de trabalho, para a máquina SHUTTLE DC 3.50 e assim organizar o fluxo dos moldes durante o set-up. Os envolvidos colaboraram com sugestões, apresentaram interesse em entender e dessa forma conseguiram compreender como aconteceria o processo, bem como sanar as dúvidas que apareceram conforme o treinamento era apresentado.

\subsection{Implantação da instrução de trabalho na máquina Shuttle DC 3.50 para organizar o fluxo dos moldes durante o set-up}

Após realizado o treinamento com todos os envolvidos no processo de set-up, ocorreu a implantação, e sua utilização iniciou-se a partir do dia 9 de setembro de 2014.

Para que todos pudessem conhecer e, se preciso, recorrer à folha de instrução de trabalho, foi entregue uma folha de instrução de trabalho a cada envolvido no processo de set-up, bem como foi fixado nos murais e na máquina SLUTTLHE DC 3.50.

No dia 26 de setembro de 2014, foi realizada a primeira avaliação dos resultados da implantação da folha de instrução e de acordo com relatos do Gestor da Produção "tudo estava fluindo melhor após o treinamento e implantação da instrução de trabalho". Ele também elogiou a cooperação de todos os envolvidos no processo de set-up e relatou que a organização dos moldes e o fluxo dos turnos estava de acordo como o planejado e esperado pela empresa.

\subsection{Apresentação dos resultados gerados com a implantação da instrução de trabalho}

No dia 9 de outubro de 2014 realizou-se outra visita à empresa para conferir os resultados obtidos após a implantação da instrução de trabalho e, desta vez, buscou-se os resultados com base nos tempos de set-up e no fluxo dos moldes conforme os turnos. 
Observou-se que o local dos moldes estava organizado e identificado com as etiquetas sugeridas, bem como tudo estava limpo e de fácil acesso, conforme Figuras 2 e 3 .

Figura 2 - Localização do estoque de moldes

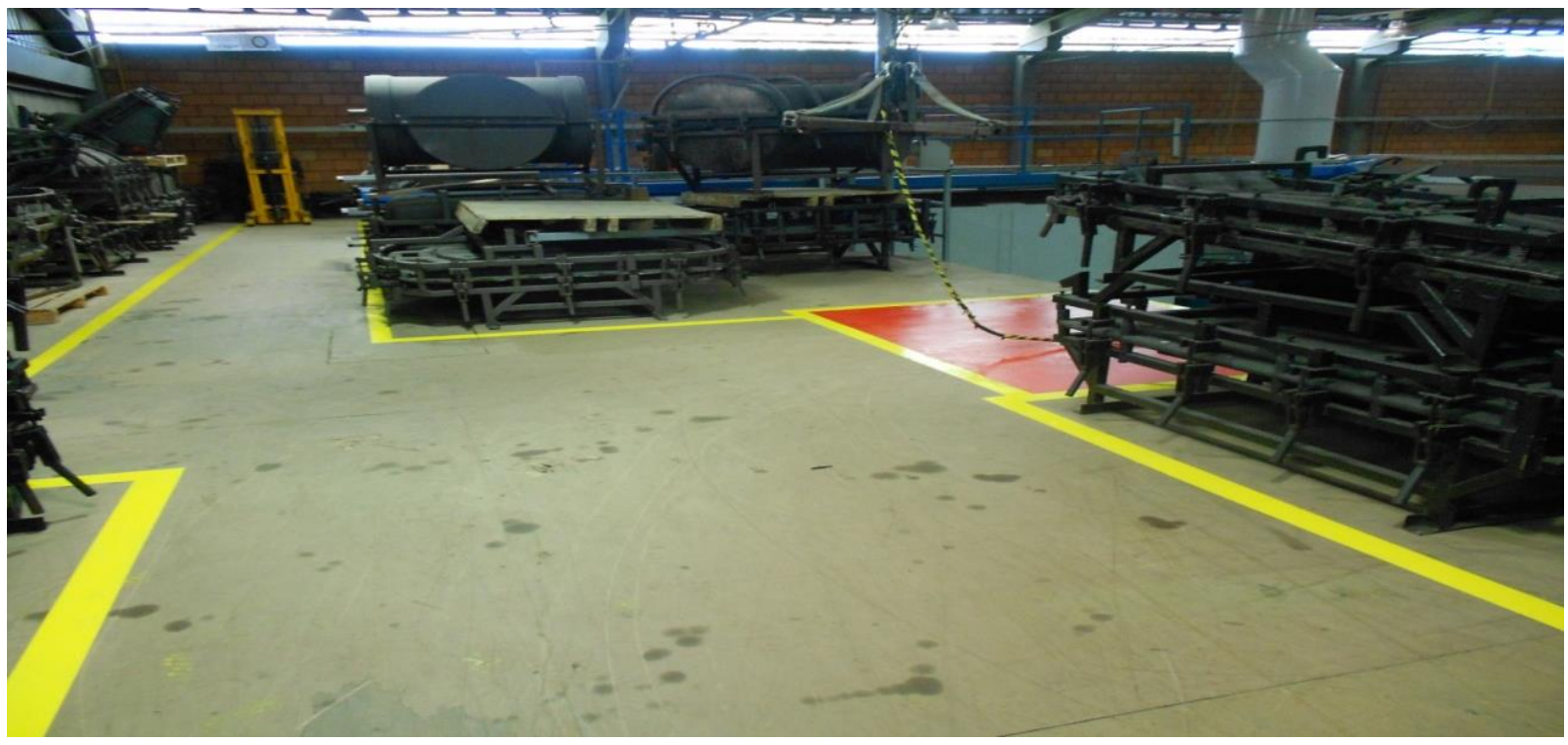

Fonte: material interno Freso (2015).

A Figura 2 apresenta a visualização da localização do estoque de moldes da Freso após a implantação, em que cada tipo de molde fica em um espaço específico, deixando-os em pilhas (um acima do outro).

Figura 3 - Identificação para localização no estoque de moldes realizada pela empresa

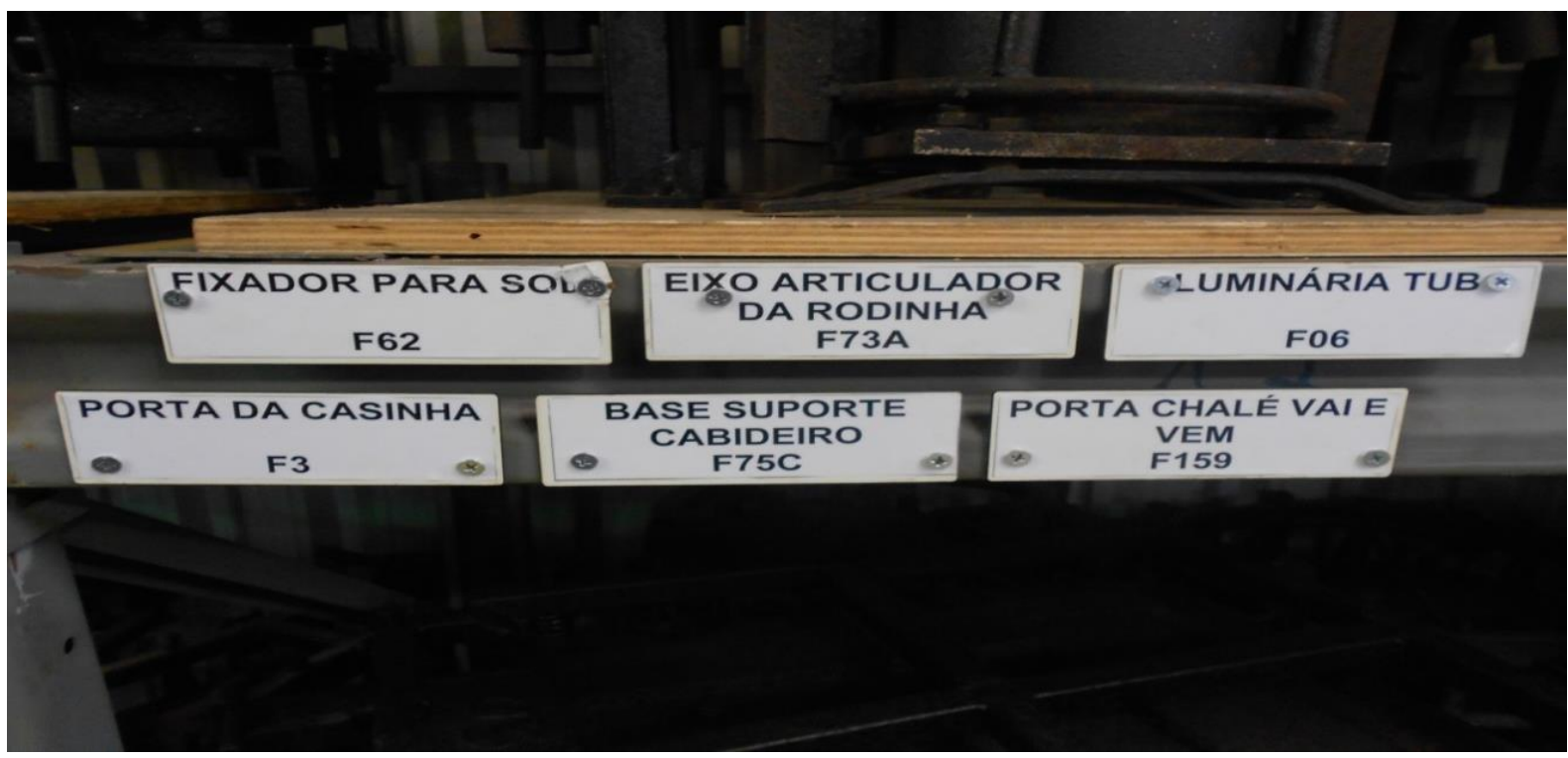

Fonte: material interno Freso (2015).

Na Figura 3, é possível observar a identificação dos moldes em seu estoque, que a empresa já utitizava e ainda utiliza para a localização dos moldes no estoque. 
É possível verificar diante das Figuras 2 e 3, bem como da entrevista informal com o gestor de produção, que a localização dos moldes e sua organização estão cada vez mais como o esperado pelo gestor, após a proposta implantada na empresa, como por exemplo: a obtenção de resultados foram satisfatórios, a facilidade de acesso, organização e a disciplina dos operadores quanto à entrega dos moldes nos seus devidos lugares.

$\mathrm{Na}$ mesma visita foram obtidos os tempos de set-up registrados durante o período de implantação da instrução de trabalho, que foi do dia 9 de setembro até o dia 9 de outrubro de 2014, obtendo 30 dias de coleta de tempos de set-up. Assim, é possível comparar os set-ups anteriores à implantação bem como os posteriores à implantação.

Então, para identificar se seria possível reduzir a oscilação no tempo de set-up, na máquina SHUTTLE DC 3.50 da empresa Freso, com a implantação da instrução de trabalho para organizar o fluxo dos moldes, elaborou-se um quadro comparativo entre os dois gráficos - o anterior à implantação realizada no primeiro semestre de 2014 e o posterior à implantação realizado no segundo semestre de 2014, conforme Quadro 3.

Quadro 3 - Resultados dos tempos de set-ups

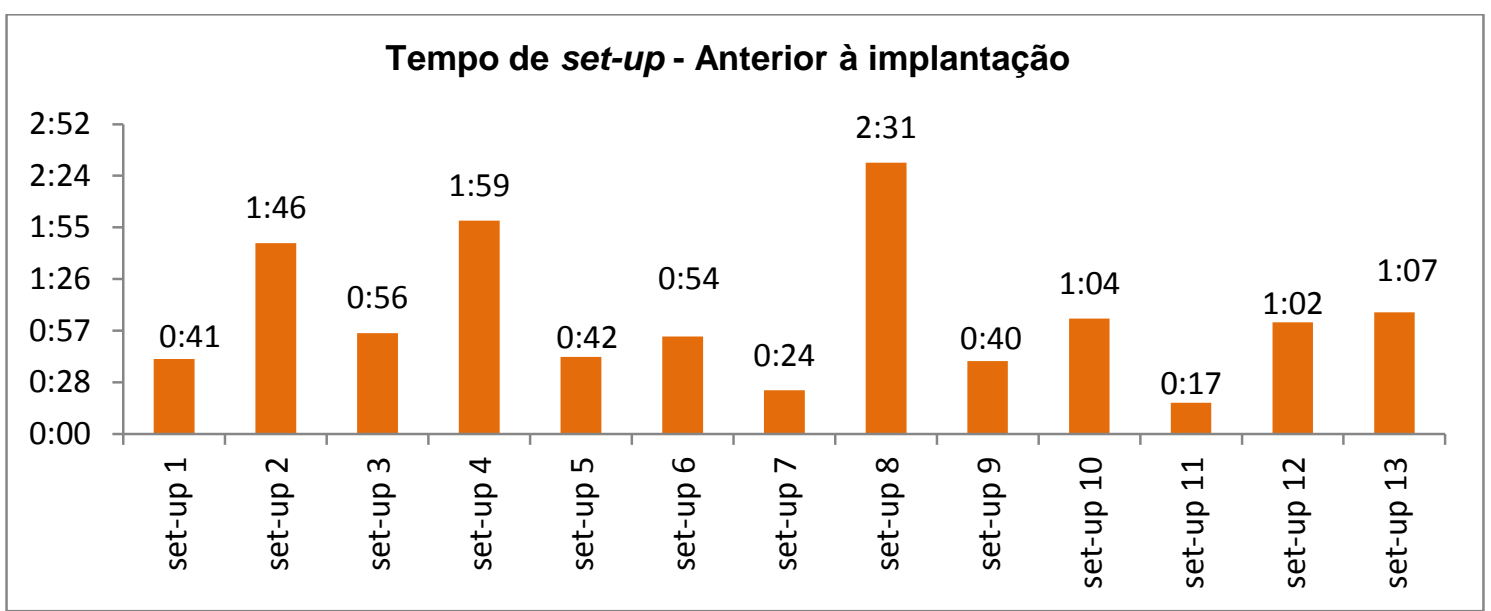




\section{Tempo de set-up - Após à implantação}

2:52

$2: 24$

$1: 55$

$1: 26$

$0: 57$

$0: 28$

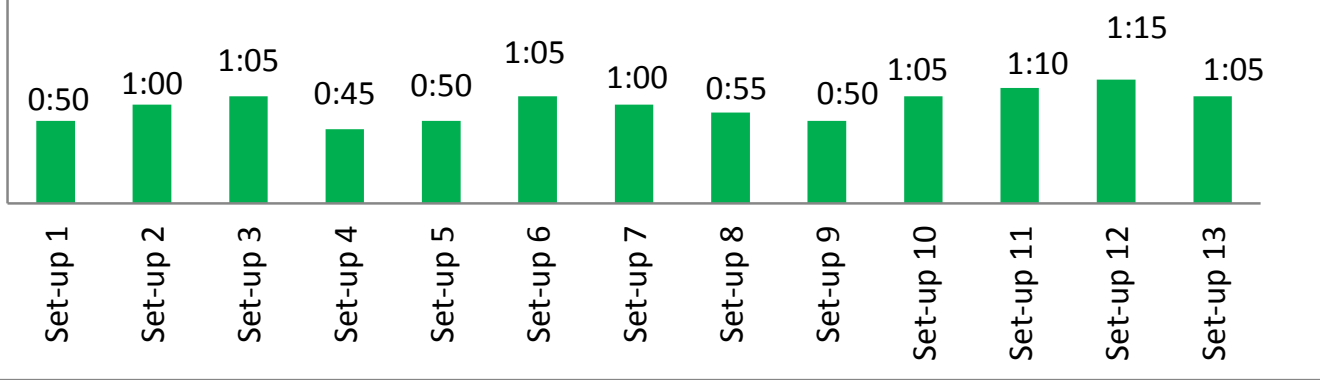

Fonte: elaborado pelos autores (2015).

Observa-se no Quadro 3 que a oscilação diminuiu após à implantação da instrução de trabalho para a organização do fluxo dos moldes, os tempos de set-ups oscilam com pouca diferença em relação aos tempos de set-ups anteriores à implantação. Verifica-se também que os tempos de set up apresentados no gráfico "anterior à implantação" possuem variação entre 17 minutos a 2 horas e 31 minutos. Enquanto o tempo de set-up no gráfico "após à implantação" ficou entre 50 minutos e 1 hora e 15 minutos. Esses tempos representam uma redução na oscilação de 134 minutos no primeiro gráfico para 25 minutos no segundo gráfico do Quadro 3.

Depois de identificado o resultado, ou seja, a redução das oscilações entre os setups, buscou-se analisar quanto de desperdício de produção a empresa conseguiu reduzir nos 13 set-ups, por meio de outro quadro comparativo entre os dois gráficos, em que o primeiro apresenta as perdas do período anterior à implantação, realizado no primeiro semestre de 2014, e o segundo apresenta as perdas no período posterior à implantação, o qual foi realizado no segundo semestre de 2014. Ambos os resultados representam as perdas em quilos por set-up, conforme Quadro 4. 
Quadro 4 - resultados das perda em quilos por set-up
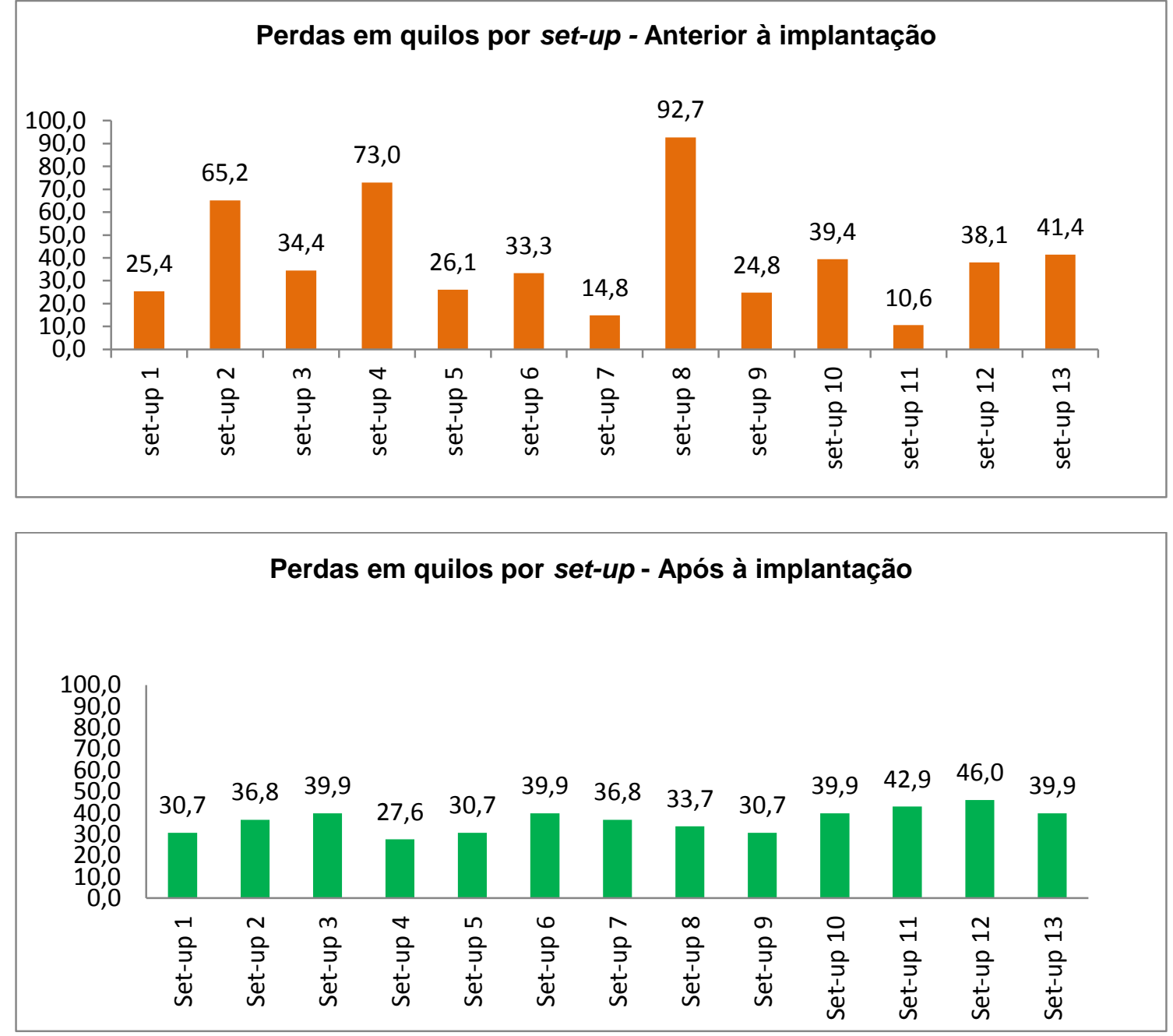

Fonte: elaborado pelo autor (2015).

Conforme observa-se no Quadro 4, as perdas de produção referentes ao período anteriormente à implantação representam $519,2 \mathrm{~kg}$, somando-se os 13 set-ups, o que corresponde a $9 \%$ da capacidade produtiva da máquina a cada mês.

Após a implantação, verifica-se no segundo gráfico no Quadro 4 que a empresa perdeu 475,29 kg de sua produção somando-se os 13 set-ups realizados, ou seja, apresentou $6 \%$ de perda da capacidade produtiva da máquina a cada mês. Isso resultou em uma redução de $3 \%$ após a implantação da instrução de trabalho, com relação ao tempo de set-up que a empresa deixa de produzir, em apenas um mês de implantação. A empresa agora poderá seguir com a implantação e aplicabilidade do projeto, e poderá atingir a meta de redução de 5\% ao mês, estipulada pelo gestor da produção. 


\section{Considerações finais}

A oscilação no tempo de set-up é um fator encontrado na empresa Freso que estava impactando na produção. Com este estudo buscou-se reduzir a oscilação no tempo de set-up, e melhorar, assim, o processo produtivo.

Além disso, as causas base para o estudo demonstram a importância de implantar alternativas de solução para que o problema estudado fosse solucionado ou minimizado, como apresentado na implantação da instrução de trabalho para a redução da oscilação no tempo de set-up na máquina SHUTTLE DC 3.50.

Um ponto também que vale destacar foi a dificuldade de encontrar literaturas próprias sobre assunto central, set-up, bem como exemplos de instruções de trabalho voltadas para o tema. Assim, para melhor entendimento e desenvolvimento do trabalho, buscou-se basear-se em estudos de artigos, nos quais se obteve informações de relevância para realizar o presente estudo.

Sugere-se, para trabalhos futuros, aplicar o processo produtivo nas demais máquinas que realizam set-up, já que o intuito do trabalho foi a implantação da instrução de trabalho para organizar o fluxo dos moldes durante o set-up apenas na máquina SHUTTLE DC 3.50.

Sugere-se também pesquisa futura sobre a importância de diminuir o tempo de set-up na máquina SHUTTLE DC 3.50 e não somente a oscilação. Assim, enfatiza-se a necessidade de realizar um benchmarking em empresas do mesmo ramo, ou que trabalhem com a mesma máquina de rotomoldagem, para ter um comparativo de tempo e verificação do andamento do set-up nas demais máquinas da produção da empresa.

\section{REFERENCIAS}

ALMEIDA, B. F. O. Método da elaboração da folha de processos em sistemas de manufatura. Juiz de Fora, 2009. 42 f. Monografia (Graduação em Engenharia de Produção) - Departamento de Engenharia de Produção,Universidade Federal de Juiz de Fora. 
ALVES, J. M; REIS, M. E. P. Um estudo de caso: um guia para se calcular o ganho originado pela redução do tempo de setup. Relatório técnico. Fortaleza: XXVIENEGEP, 2006. 9p.

CORRÊA, H. L; CORRÊA, C. A. Administração de produção e operações: manufatura e serviços: uma abordagem estratégica. 2.ed. São Paulo: Atlas, 2009.

DIAS, M. A. P. Administração de materiais - uma abordagem logística. 4.ed. São Paulo: Atlas, 1996.

JUNIOR, I. M; CIERCO, A. A; ROCHA, A. V; MOTA, E. B; LEUSIN, S. Gestão da Qualidade. 8.ed. Rio de Janeiro: Editora FGV, 2006.

LACOMBE, F. J. M. Recursos humanos princípios e tendências. São Paulo: Saraiva, 2011.

MARTINS, P.G; LAUGENI, F.P. Administração da produção. 2.ed. São Paulo: Saraiva, 2010.

MESSIAS, S. B. Manual de Administração de materiais: planejamento e controle dos estoques. 5.ed. Rio de Janeiro: Atlas, 1997.

MILKOVICH, G. T; BOUDREU, J. W. Administração de Recursos Humanos. 1.ed. 8.reimpr. São Paulo: Atlas, 2010.

MOURA, R. A. Armazenagem e distribuição física. 2.ed. São Paulo: IMAM, 1997.

Sistemas e técnicas de movimentação e armazenagem de materiais. 5.ed. rev. São Paulo: IMAM, 2005. (Série Manual de Logística, v. 1.)

OLIVEIRA, D. P. R. Sistemas, organização e métodos - uma abordagem gerencial. 12.ed. São Paulo: Atlas, 2002.

PAIM, R; CARDOSO, V; CAULLIRAUX, H; CLEMENTE, R. Gestão de processos, pensar, agir e aprender. Porto Alegre: Bookman, 2009.

SLACK, N; CHAMBERS, S; JOHNSTON, R. Administração da produção. 3.ed. São Paulo: Atlas, 2009.

SPECTOR, P. Psicologia nas organizações. São Paulo: Saraiva, 2006. 
TEODORO, S. G.; GARCIA, G. L.; NAGASHIMA, S. M.; AUGUSTO, L. A. M.; LEITE, R. V. Integrando o arranjo físico, o fluxo de materiais e a qualidade de vida na Danisco Brasil Ltda. 2002. 45 f. Relatório de Estágio - Curso de Administração, Faculdades integradas “Antônio Eufrásio de Toledo”, Presidente Prudente, 2002.

TUBINO, D.F. Planejamento e controle da produção: teoria e prática. 2.ed. São Paulo: Atlas, 2009.

Recebimento dos originais: 06/08/2015

Aceitação para publicação: 30/08/2015 